\title{
A RELAÇÃO FAMÍLIA-ESCOLA EM UM TERRITÓRIO DE ALTA VULNERABILIDADE SOCIAL
}

\section{The family-school relationship in a territory of high social vulnerability}

\author{
Cristina Ferreira de Assis - Universidade Federal de Ouro Preto/Brasil
}

\begin{abstract}
RESUMO: Este trabalho traz os resultados de uma pesquisa cujo objetivo principal foi analisar a relação família-escola em um meio de alta vulnerabilidade social. Trata-se de um estudo do caso de uma escola pública da periferia de Mariana-MG. Como metodologia, utilizou-se de observação orientada e entrevistas semiestruturadas com sujeitos que estabelecem diferentes relações com a escola, como pais, comunidade, gestores e funcionários da instituição escolar. Os resultados demonstram que o efeitoterritório contribui para a manutenção das desigualdades sociais na escola, assim como no processo de escolarização, embora os entrevistados identifiquem e vivenciem esses efeitos de formas muito distintas.
\end{abstract}

Palavras-chaves: Relação família-escola, vulnerabilidade social, camadas populares.

ABSTRACT: This paper presents the results of a research whose main objective was to analyze the family-school relationship in a medium of high social vulnerability. It is a case study in a public school on the outskirts of Mariana-MG. The methodology used is oriented observation and semi-structured interviews with subjects that establish different relationships with the school, as parents, community, managers and employees of the school. The results shows that the territorial effect contributes to the maintenance of social inequalities in school, as well as in the schooling process, although the interviewees identify and experience these effects in very different ways.

Key-words: Relationship between family and school, social vulnerability, popular classes.

\section{INTRODUÇÃO}

As pesquisas sobre a relação entre família e escola fazem parte da literatura sociológica desde as décadas de 50 e 60. Essa discussão articula as dimensões micro e macro da educação, entre sistema de ensino e instituição escolar, como também a partir do desenvolvimento de estudos que investigam, numa análise sociológica no interior das dinâmicas familiares e sua relação com os processos de escolarização.

Educação, Psicologia e Interfaces, Volume 3, Número 2, p. 21-33, Maio/Agosto, 2019.

ISSN: 2594-5343. DOI: https://doi.org/10.37444/issn-2594-5343.v3i2.135 
Dessa forma, os estudos vêm avançando na compreensão dos desdobramentos dessa relação, seja com foco nas mudanças nas dinâmicas e nos modos de exercício da autoridade intrafamiliar (MONTANDON, 2005), nas transformações econômicas e sociais que vêm arrolando estas duas instituições (SINGLY, 2007), na interculturalidade das duas instâncias socializadoras (SILVA, 2009), ou ainda na influência das práticas educativas familiares no sucesso escolar dos alunos (LAHIRE, 2008), dentre outros. Casos de fracasso ou insucesso escolar, docentes desiludidos, capitais culturais socialmente dominantes, dentre outros fatores também compõem a gama de estudos que envolvem a relação família e escola.

No Brasil, as Políticas públicas e a mídia envolvem-se nessa questão e disseminam um discurso que, na maioria das vezes, responsabiliza a família pela falta de diálogo com a escola, principalmente nos casos de insucesso escolar das crianças (RESENDE, SILVA, 2016; SILVA, 2009).

Sabe-se que a escola é um espaço social influenciado pelos problemas e ou situações vivenciadas ao seu redor, principalmente em locais de pouca extensão territorial e periféricos. Seja pelo baixo capital cultural das famílias e da comunidade, seja pela falta de esclarecimento e de acesso às informações, seja pelo receio da escola em atribuir funções administrativas ou pedagógicas às pessoas externas ao meio escolar. O que é perceptível é que, em geral a relação de parceria entre as duas instituições socializadoras - escola e família - é bem vista e desejada, mas nem a escola e nem a família dispõem de meios concretos para sua efetivação.

Com base nas discussões trazidas pela literatura sobre o tema e a necessidade de compreender melhor a relação família e escola em bairros periféricos de pequenas cidades assim como a influência dessa relação no processo de escolarização, o objetivo principal da pesquisa a ser apresentada foi investigar como se dá a relação família-escola em um território de alta vulnerabilidade social.

Seguindo uma abordagem qualitativa, a pesquisa teve como proposta investigar uma escola da rede pública municipal de educação básica, situada em um bairro da periferia do munícipio de Mariana, em Minas Gerais, ao longo de dois anos, sendo o bairro identificado pelos moradores assim como pelos noticiários locais como uma região de alta vulnerabilidade social. A pesquisa contou ainda com o suporte dos arquivos do município assim como com as visitas observacionais e um diário de campo cuja 
triangulação das fontes permitiu o cruzamento de dados para que fosse alcançado o objetivo proposto. Nesse artigo, serão privilegiados os resultados das entrevistas ${ }^{1}$.

A justificativa dessa proposta corroborada a partir da literatura consultada, reafirma a impossibilidade de pensar a escola sem compreender que ela é, inevitavelmente, um lugar de reprodução cultural e social. Na escola se refletem os modelos educativos familiares, além de toda e quaisquer situações variáveis envolvendo as pessoas e comunidades de seu entorno. Isso também fica evidenciado no trabalho de Alves et al. (2012) ao afirmarem que a influência do meio e dos fatores de risco sociais podem ser tão grandes, que as possibilidades de reprodução social, especialmente aquelas por meio de estratégias educativas, tornam-se comprometidas.

Atrelado a outros fatores, o contexto do isolamento territorial e social acaba se reproduzindo na escola de forma negativa. Isso significa que, independentemente da educação recebida pelas crianças e adolescentes em casa, a escassez de recursos sociais e o isolamento desses territórios levam a escola a tornar-se tanto uma importante e quase única presença dos bens e serviços do aparato público no território, quanto também, um espaço efetivo de reprodução da situação social vulnerável vivenciada no bairro. Assim, fatores como: violência, furto, evasão ou criminalidade acabam tornando-se naturalizados e aceitáveis para os jovens que conviveram ou observaram outros com os mesmos hábitos $^{2}$. Ou seja, o efeito de pares é maior do que as características familiares isoladamente. Dessa forma, a busca da escola em promover um modelo educacional isolado e afastado dos problemas ou demais situações externas vivenciadas no local tornam a promoção do saber e a tarefa de educar sistematicamente um desafio.

\section{MATERIAIS E MÉTODOS}

Pesquisas recentes no Brasil têm investigado a relação entre territórios de alta vulnerabilidade social e escolarização/oferta educacional. Estudos como os de Koslinski (2009), Queiroz (2009), Batista (2012), Alves et al. (2012), Érnica (2011) e outros, embora tenham como centralidade a relação entre desigualdades socioespaciais e desigualdades escolares em grandes metrópoles, contribuem tanto para a compreensão dessa relação em outros contextos, quanto para o aprofundamento dos conceitos elucidados sobre o tema, tendo-se o cuidado, a partir de um rigor teórico e metodológico, 
de observar, anunciar e analisar as especificidades de um território socialmente vulnerável em cidades interioranas e de pequeno porte, como é o caso do município de Mariana-MG, contexto do presente estudo. Para Koslinski (2009), em territórios de alta vulnerabilidade social, além de haver escassez de serviços privados, também há uma baixa cobertura de equipamentos públicos que possam garantir direitos sociais.

Nesse sentido, partindo-se da revisão de literatura apresentada, para a seleção da escola levou-se em conta, não somente a sua reconhecida vulnerabilidade social pelos moradores da cidade, como também foi realizada uma pesquisa exploratória nos dados do Instituto Nacional de Estudos e Pesquisas Educacionais Anísio Teixeira (INEP) sobre as escolas públicas de educação básica de Mariana, no tocante aos indicadores Índice de Desenvolvimento da Educação Básica (IDEB) e Nível Sócio Econômico (NSE) das escolas, assim como informações obtidas sobre as escolas junto à Secretaria Municipal de Educação de Mariana. Diante desse levantamento foi possível identificar a escola selecionada como uma das que apresentavam menores índices nas avaliações oficiais, sendo o seu IDEB 3,2 em 2009 e 3,6 em 2011 (abaixo da média de 4,6 do município), e com NSE dos alunos atendidos situado nos níveis "muito baixo, baixo e médio-baixo"3 (INEP, 2011).

Neste contexto de carência de recursos sociais e econômicos, a escola torna-se o centro de referência pública local. E como nestes locais as pessoas encontram-se, muitas vezes, física e simbolicamente isoladas, os problemas inerentes ao território acabam refletindo-se no desenvolvimento interno da escola, impondo-lhe desafios que ultrapassam as suas condições de solução, como é o caso da violência contra os professores e os próprios alunos, do consumo e tráfico de drogas entre os estudantes, dos altos índices de evasão e reprovação, entre outros, aspectos que acabam prejudicando as demais atividades inerentes ao papel da escola. Tal interferência do território com altos níveis de vulnerabilidade social na qualidade da oferta educacional, no desempenho dos alunos e, consequentemente, nas avaliações do IDEB de tais escolas foi denominado "efeito território" por Batista et al. (2013).

Após a seleção da escola, procedeu-se a uma intensa procura por documentos nos arquivos do estabelecimento de ensino e do município que fornecessem informações sobre a criação do bairro e a construção da escola. Em seguida, iniciaram-se as visitas observacionais no espaço comunitário onde a escola se insere e na própria instituição

Educação, Psicologia e Interfaces, Volume 3, Número 2, p. 21-33, Maio/Agosto, 2019. 
escolar, utilizando-se assim um caderno de campo para registros, seguindo-se um roteiro orientador da pesquisa observacional.

Além da observação e da pesquisa documental também foram realizadas entrevistas semiestruturadas com sujeitos que ocupam ou ocuparam cargos na escola, pais de alunos ou responsáveis e membros da comunidade local a fim de que, por meio dessa escuta, fosse possível construir uma análise da relação família-escola considerando-se os diferentes olhares e percepções sobre o bairro e a própria escola. Ao todo foram realizadas 13 entrevistas, discriminadas a seguir: um professor (que não residia no bairro) - com maior tempo de atuação profissional na escola; dois diretores - um que atuava na escola na época da pesquisa e um anterior com maior tempo de atuação na instituição; um funcionário da escola (que não residia no bairro) com maior tempo de atuação no estabelecimento de ensino; quatro moradores do bairro (duas pessoas que trabalhavam na escola e que viviam no bairro; duas pessoas que viviam no bairro e que atuavam em uma associação comunitária); e, por fim, cinco famílias que tinham um ou mais filhos na escola.

Para a coleta de dados, foram utilizados três roteiros de entrevistas compostos por quatro blocos temáticos. Os roteiros elaborados tanto para os funcionários da escola quanto para as famílias e os outros moradores do bairro visaram investigar as percepções, sentimentos e pontos de vista dos sujeitos acerca da escola, dos processos de escolarização e da relação social estabelecida entre escola, famílias e comunidade. Desta forma, pretendeu-se obter dados que permitissem análises distintas das perspectivas construídas por pessoas com capitais culturais, sociais e econômicos diferentes sobre a escola e a escolarização.

As entrevistas basearam-se nas seguintes categorias que fundamentaram os blocos temáticos dos roteiros semiestruturados: 1) A relação família-escola no território socialmente vulnerável, 2) A importância da escola enquanto instituição social e educacional, 3) A influência da família, do bairro e demais organizações sociais na escola e 4) Mudanças na legislação e nas políticas públicas e a influência na escola.

\section{RESULTADOS E DISCUSSÃO}

Educação, Psicologia e Interfaces, Volume 3, Número 2, p. 21-33, Maio/Agosto, 2019.

ISSN: 2594-5343. DOI: https://doi.org/10.37444/issn-2594-5343.v3i2.135 
Ao longo de dois anos de investigação foram diversos os momentos de observações em diferentes turnos na escola. Na segunda fase da pesquisa partiu-se para a metodologia central, ou seja, a realização das entrevistas com base nos roteiros previamente testados. Sendo assim, após a transcrição e arquivamento dos áudios, foram selecionados alguns trechos dos depoimentos que contribuíram para compreender as questões anunciadas na pesquisa.

No tocante ao tópico 1) "relação família-escola em um território vulnerável", segundo os relatos dos sujeitos entrevistados, havia uma "boa" relação entre a escola e as famílias do bairro. De acordo com os depoimentos, uma "boa relação" consistia em uma forma de interação sem grandes conflitos e com a existência de um tipo de parceria entre escola e comunidade. Cabe apontar e chamar a atenção para os adjetivos - boa, bom constantemente utilizados pelas famílias entrevistadas ao se referirem aos contatos com a escola do bairro. As famílias não demonstraram em seus relatos, algum tipo de objeção ou insatisfação frente às atitudes da escola, podendo se identificar um certo “conformismo", ou submissão (cultural, política e social) em relação à instituição escolar.

O que se pode inferir com essa pesquisa é que família e escola têm expectativas distintas no que tange ao processo de escolarização. Fato que também vem sendo demarcado pela literatura sociológica sobre o tema. Por um lado, a escola espera que as famílias eduquem moralmente seus filhos de forma que estes cheguem à escola aptos a receberem o saber formal e sistematizado, ou seja, apresentando uma certa "docilidade" necessária às aprendizagens escolares (BOURDIEU, 2004), como argumenta a coordenadora pedagógica da escola: “a gente espera mais participação (das famílias). Que eles vejam a escola como uma projeção do futuro" (Pedagoga C.).

Em contrapartida, as famílias entrevistadas, com pais e avós pouco escolarizados, almejam uma progressão social para suas crianças e jovens, ou seja, uma mobilidade social que, no entendimento dos pais, é dependente da escolarização. No depoimento de uma mãe torna-se evidente a expectativa em relação a um futuro "melhor" para o filho: "daqui uns anos ele pode formar, tirar uma carteira de motorista, comprar um carro, ter tudo na vida, minha filha" (Mãe E).

Nota-se ainda, que a ideia de futuro é um campo aberto e cheio de possibilidades no imaginário destas famílias. Porém, à escola é conferida a "missão de salvar" este aluno da vida precária, além, é claro, de fornecer as bases para o sucesso.

Educação, Psicologia e Interfaces, Volume 3, Número 2, p. 21-33, Maio/Agosto, 2019. 
Outro ponto importante para a análise foi a forma como os entrevistados se referiam ao assunto "vulnerabilidade social". Segundo os relatos das pessoas que residiam no bairro, por exemplo, aquele era um "bom lugar pra se viver", "é calmo e tranquilo, embora com certa violência”. A mesma percepção não pode ser identificada nos depoimentos dos entrevistados que não residiam no bairro. Eles demonstraram em seus depoimentos um visível receio do lugar, em virtude de um alto índice de violência presente no bairro, como podemos identificar no relato a seguir:

Tem pessoa que sai daqui horrorizada pela falta de educação, mas isso aí é reflexo do que eles vivem aqui fora. E a escola não tá dando conta de solucionar estes problemas. Solucionar não né, sanar, porque solução, solução, só Deus é quem tem (Professora O).

É possível interpretar os depoimentos dos moradores do bairro que minimizam os efeitos da violência no local enquanto demonstração de um sentimento de pertencimento ou de construção identitária, ou mesmo, a um "conformismo social" na perspectiva de Norbert Elias conforme expresso em sua obra Os estabelecidos e os outsiders $(2000)^{4}$. Assim, embora estas famílias estejam em um território de alta vulnerabilidade social e vivenciem a precariedade dessa realidade, se opor a isso é uma forma de ir contra os padrões e crenças do local. Uma outra interpretação para tal comportamento pode ser encontrado em Érnica e Batista (2011), que defendem que as famílias que residem no território vulnerável tendem a tornar-se um continuиm indiferenciado dele. Uma das consequências disso é que, em geral, pais, alunos e a escola não conseguem superar os padrões sociais e culturais do território para a criação de um ambiente propriamente escolar.

A defesa do bairro e a busca de minimização dos problemas vivenciados pela população também foram observadas em outros depoimentos. Ao fazerem a descrição do bairro, moradores apontaram a violência como um dos grandes problemas sociais vivenciados pelos habitantes do território, embora a afirmação de que este é um "bom lugar para se viver" revele certo contraste nas falas, como no exemplo a seguir: "É uma comunidade assim muito mal vista, pelo menos no meu ponto de vista. (Moradora do bairro J). Ou ainda: o que a gente tem mesmo é a coisa das drogas, não vejo nada demais assim, eu acho um bairro tranquilo, em vista de muitos que eu vejo por aí a fora, ainda acho um bairro tranquilo (Moradora do bairro $\mathrm{N}$ ).

Educação, Psicologia e Interfaces, Volume 3, Número 2, p. 21-33, Maio/Agosto, 2019. 
Se constituindo um aglomerado socialmente vulnerável e estigmatizado pela cidade, como um local social e culturamente "inferior", a população do bairro procura a todo custo, criar os vínculos necessários para a sua sobrevivência (material e simbólica). E em um movimento de contra-estigmatização (ELIAS, 2000), os sujeitos moradores do bairro afirmam um certo gosto por ali morar e viver, socialmente construído pelas urgências da necessidade (BOURDIEU, 2004).

Para entender os processos de estigmatização e sua mecânica, seria necessário um exame minucioso dos processos de construção de uma certa imagem de si mesmo e do grupo social ao qual pertence, ou seja, da posição que cada indivíduo ocupa no interior do grupo e em relação aos outros grupos sociais. E, mesmo que, no escopo dessa pesquisa, esse exame não tenha sido possível, pode-se afirmar, na esteira de Elias (2000, p. 188), que os moradores do bairro investigado constroem uma visão sobre si mesmos afetada não somente pelas experiências vivenciadas no bairro, mas também pelas experiências do que os outros dizem e pensam sobre o bairro e sobre as pessoas que ali moram. A percepção positiva do lugar, que oscila entre o "bom e o ruim", ajuda as famílias a se posicionarem em um ponto mais ou menos confortável (material e simbolicamente) em relação ao grupo social mais amplo do território.

Com relação ao público atendido pela escola, foi possível identificar nos relatos dos entrevistados, uma visão sobre os alunos que tende a ser homogeneizadora, denominando-os como indisciplinados, desinteressados e/ou apáticos. De acordo com a pesquisa de Érnica e Batista (2011) existe uma forte tendência desses jovens vivenciarem os estigmas e preconceitos recaídos sobre eles, e ainda reproduzirem o padrão de sociabilidade fomentado pela segregação social que não condiz com o funcionamento da escola. Praticamente todas as sociedades estigmatizam outros grupos como sendo grupos de status inferiores ou de menor valor. Mas a natureza do preconceito, o motivo pelo qual um grupo estabelecido encara outro grupo outsider como estando em uma posição mais baixa e tendo menos valor, permanece normalmente sem esclarecimento (ELIAS, 2000).

De acordo com Koslinski e Ribeiro (2009) e Érnica e Batista (2011), em territórios de alta vulnerabilidade social os estigmas por parte da direção da escola e dos professores acabam sendo inevitáveis. Talvez ainda seja prudente dizer que se universalizou o acesso da população a um modelo escolar que não pode ser universalizável, pois traz em suas bases históricas e culturais o desenvolvimento de um modelo educacional voltado para

Educação, Psicologia e Interfaces, Volume 3, Número 2, p. 21-33, Maio/Agosto, 2019. 
um público muito diferente do atual. O resultado disso são as desigualdades sociais que aparentam uma forma de exclusão branda; os alunos continuam matriculados, mas o modelo de ensino é incapaz de lhes assegurar condições de aprendizado e de desenvolvimento. Ou seja, de acordo com os autores, o modelo escolar não está preparado para lidar com as diversidades econômicas, sociais e culturais do público em questão, especialmente tratando-se de um território de alta vulnerabilidade social. Notoriamente, os resultados apresentados por esta pesquisa em questão apontam desfechos similares.

Quando questionados sobre como a escola lida com os problemas ou situações vivenciadas pela comunidade local, os relatos dos entrevistados (diretores e funcionários da escola) não apresentam evidências de uma ação efetiva da escola, embora em questões anteriores todos relatassem reflexos da violência do bairro na escola, como pode ser verificado a seguir por uma mãe e uma funcionária da escola:

\footnotetext{
Muitas pessoas, professores, por exemplo, costumam ter medo de dar aula aqui na escola porque tem alunos agressivos, eu acho que atrapalham um pouco (a escola). Porque o bairro aqui é bem agressivo né... Alguns alunos (Mãe A). (...) Até nas brincadeiras das crianças elas brincam de polícia/ladrão, traficante e polícia. Tudo que eles às vezes vão fazer já estão brigando, é ameaçar, falar que vai matar, entendeu (Inspetora Y).
}

Tal fato também pode ser corroborado pela pesquisa de Érnica e Batista (2011), ao argumentarem que quando ocorrem situações de conflito fora da escola, acabam repercutindo em episódios de violência no interior dela. Contudo, nem sempre ou quase nunca a instituição consegue minimizar esses episódios. Se os adolescentes de uma comunidade abandonaram ou desistiram da escola e se engajaram em crimes, outros adolescentes terão propensão a ver esses fatos como aceitáveis. Certamente todas essas situações vivenciadas pelos moradores e pela escola repercutem nas avaliações, sejam elas formais ou não formais. As notas baixas da escola pesquisada nas avaliações nacionais, além de não ser uma novidade em escolas situadas em locais vulneráveis, representam um reflexo desta falta de projeção de melhoria nos índices de reprovação, evasão e indisciplina, ou ainda de fatores de risco de morte dos jovens, presentes em um território de alta vulnerabilidade social. $\mathrm{O}$ fato também pode ser corroborado pelas pesquisas de Érnica e Batista (2011) ao argumentarem que quanto maior é o índice de vulnerabilidade social em um território, menores são as notas das escolas nas avaliações nacionais.

Educação, Psicologia e Interfaces, Volume 3, Número 2, p. 21-33, Maio/Agosto, 2019.

ISSN: 2594-5343. DOI: https://doi.org/10.37444/issn-2594-5343.v3i2.135 


\section{CONSIDERAÇÕES FINAIS}

Vários fatores tentam explicar a diferença entre a qualidade das escolas situadas em vizinhanças onde há maior concentração de pobreza. Alguns se relacionam com a ideia de infraestrutura e até mesmo com a capacidade de gestão da escola. No entanto, a pesquisa de campo assim como a bibliografia consultada indicaram que a influência do território socialmente vulnerável é marcante e talvez possa ser fator dominante neste processo. Embora seja impossível, dados o recorte e a metodologia empregados para a realização da pesquisa, isolar essa "influência" de outros indicadores e variáveis sociais e escolares, as fragilidades e a precariedade das condições de existência vivenciadas pelos moradores do local investigado e as formas de reprodução dessas condições no espaço escolar, não puderam ser negligenciados nas análises.

As entrevistas demonstraram o lugar de destaque ocupado pela escola no bairro, ao se constituir em uma das grandes referências para a população que ali vive. Tal centralidade também é observada na literatura utilizada neste estudo, demonstrando que em locais periféricos existe essa forte tendência. Contudo também foi possível inferir que os males do território socialmente vulnerável se reproduzem no interior da escola, e fazem dessa um meio de reprodução de desigualdade social do bairro.

Embora não fosse objeto desta pesquisa, também foi possível inferir que a escola lida com o chamado efeito território. Com isso, a influência do meio é negativa no desenvolvimento da escola, perpetuando-se, assim, os males já enfrentados no território.

Já para aqueles que residem no bairro, a violência é reconhecida, mas é minimizada em suas falas. As mães e moradoras do bairro entrevistadas demonstraram mais receio com relação ao envolvimento dos filhos com as drogas do que necessariamente com a violência. Já para os funcionários da escola, tanto o índice de violência quanto as drogas influenciam negativamente a vida de quem mora no bairro e de quem nele chega para trabalhar. Nos depoimentos de funcionários mais antigos, houve o reconhecimento de que essa é uma realidade presente há anos na escola, mas que isso não os atinge a ponto de provocar medo. Em contrapartida, para os funcionários mais novos, essa é uma realidade ainda incomum a ser enfrentada, e existe receio por parte daqueles que são direcionados para trabalhar na escola, causando, por inúmeras vezes, a desistência dos cargos antes mesmo de iniciarem as atividades na escola. 
Considera-se, por fim, que a escola consegue manter uma relação sem grandes atritos com as famílias, de acordo com as entrevistas e com as visitas observacionais. De certa forma, a instituição vem se adaptando, mesmo que de modo frágil, ao local e às condições sociais e educacionais inerentes. O baixo capital cultural das famílias, em geral, as impede de se aprofundarem em questões mais burocráticas, de fazerem sugestões ou mesmo de reclamarem e exigirem melhorias na escola. Estas famílias, mais do que outras entregam seus filhos à escola, como se a mesma assumisse a tarefa de garantir aos seus filhos, no futuro, alguma promoção social e/ou econômica.

Concluindo, a pesquisa cumpriu seus objetivos ao trazer para a discussão o caso de uma escola em uma cidade do interior de Minas Gerais que se localiza em um território vulnerável. Embora a pesquisa se restrinja a uma única escola, traz em si um potencial de generalização e elementos importantes, capazes de contribuir para os estudos a respeito das escolas situadas em territórios de alta vulnerabilidade social, demonstrando que, mesmo quando tratamos de cidades menores e interioranas, o território vulnerável influencia de forma negativa o desenvolvimento da escola, nas notas em avaliações estaduais e nacionais e no comportamento dos alunos. A escola - e também seus funcionários, gestores e professores -, se esquiva, em grande parte das vezes, sem o apoio pedagógico, político e econômico do sistema necessário, e se mantém como pode, diante de uma realidade social tão complexa.

\section{Notas de rodapé}

1 Para a construção desse artigo, em especial, privilegiamos as análises das entrevistas. Demais resultados da pesquisa poderão ser encontrados em outros espaços. É preciso ressaltar que todos os participantes autorizaram a reprodução de suas falas assinando o Termo de Consentimento Livre e Esclarecido a ser aprovado pelo então Comitê de Ética da Universidade no início da pesquisa.

${ }^{2}$ Os autores chamam de modelo epidêmico o fato de os pares influenciarem-se mutuamente. Contudo, os autores Jencks e Mayer (1990) criticam o modelo epidêmico por este partir do pressuposto de que o mau comportamento é contagioso, quando para eles essa perspectiva ignora que os indivíduos não são igualmente suscetíveis às influências da vizinhança ou da escola (KOSLINSKI, RIBEIRO, 2009).

${ }^{3}$ As medidas de NSE são calculadas pelo INEP com dados da Prova Brasil e da Avaliação Nacional da Educação Básica (ANEB). Mais informações sobre a medida NSE podem ser acessadas nas notas técnicas do Instituto INEP.

Educação, Psicologia e Interfaces, Volume 3, Número 2, p. 21-33, Maio/Agosto, 2019.

ISSN: 2594-5343. DOI: https://doi.org/10.37444/issn-2594-5343.v3i2.135 
${ }^{4}$ A obra de Norbert Elias (2000) elucida acerca da intensa pressão pelo conformismo e pelo controle demasiado da vizinhança em casos de opiniões contrárias aos padrões tradicionais do local.

\section{REFERÊNCIAS BIBLIOGRÁFICAS}

ALVES, Luciana; CARVALHO-SILVA, Hamilton Harley; BATISTA, Antônio Augusto Gomes. Esforços educativos de mães num território de alta vulnerabilidade social: um estudo de caso. Informe de Pesquisa n6. Centro de Estudos e Pesquisas em Educação, Cultura e Ação Comunitária - Cenpec, São Paulo, out. 2012.

BOURDIEU, Pierre. A escola conservadora: as desigualdades frente à escola e à cultura. In: NOGUEIRA, Maria A.; CATANI, Afrânio (orgs.). Escritos de educação: Pierre Bourdieu. Petrópolis: Vozes, 2004.

BOURDIEU, Pierre. Os três estados do capital cultural. In: NOGUEIRA, Maria A.; CATANI, Afrânio (orgs.). Escritos de educaçãa: Pierre Bourdieu. Petrópolis: Vozes, 1998.

ÉRNICA, Maurício; BATISTA, Antônio A. G. Educação em territórios de alta vulnerabilidade social na metrópole: um caso na periferia de São Paulo. Informe de Pesquisa n'3, Centro de Estudos e Pesquisas em Educação, Cultura e Ação Comunitária - Cenpec, São Paulo, nov. 2011.

ELIAS, Norbert. Os estabelecidos e os outsiders. Rio de Janeiro: Jorge Zahar Editor Ltda, 2000.

INEP. Instituto Nacional de Estudos e Pesquisas Educacionais Anísio Teixeira. Indicadores educacionais. Brasilia, INEP, 2011. Disponível em : <http://portal.inep.gov.br/web/guest/indicadores-educacionais> Acesso em 20/10/17.

KOSLINSKI, Mariane C.; RIBEIRO, Luiz Cesar Q. A cidade contra a escola? O caso do município do Rio de Janeiro. In: Revista Contemporânea de Educação. Vol.4. n ${ }^{\circ}$, 2009.

LAHIRE, Bernard. O homem plural: os determinantes da ação. Petrópolis: Vozes, 2002 .

RESENDE, Tânia F.; SILVA, Gisele F. A relação família-escola na legislação educacional brasileira (1988-2014). Ensaio: aval. pol. públ. Educ., Rio de Janeiro, v.24, n. 90, p. 30-58, jan./mar. 2016. Disponível em:

<www.scielo.br/pdf/ensaio/v24n90/1809-4465-ensaio-24-90-0030.pdf > .Acesso em: 22 de outubro de 2017.

SETTON, Maria da Graça Jacintho. Um novo capital cultural: pré - disposições e disposições à cultura informal nos segmentos com baixa escolaridade. In: Revista Educação e Sociedade, Campinas, vol. 26, n. 90, p. 77-105, Jan./Abr. 2005. Disponível em: 〈http://www.scielo.br/pdf/\%0D/es/v26n90/a04v2690> Acesso em: 02/01/2017.

Educação, Psicologia e Interfaces, Volume 3, Número 2, p. 21-33, Maio/Agosto, 2019.

ISSN: 2594-5343. DOI: https://doi.org/10.37444/issn-2594-5343.v3i2.135 
SILVA, Albany M. Dilemas do voluntariado na educação em aracaju/SE. In: Anais. IV Jornada Internacional de Políticas Públicas. São Luís - MA, 25 a 28 de agosto 2009. Disponível em: < http://www.joinpp.ufma.br/jornadas/joinppIV/OLD/eixos_OLD/11.\%20Impasses\%20e \%20Desafios\%20das\%20Politicas\%20de\%20Educa\%C3\%A7\%C3\% A3o/DILEMAS\% 20DO\%20VOLUNTARIADO\%20NA\%20EDUCA\%C3\%87\%C3\%830\%20EM\%20A RACAJU\%20SE1.pdf> Acesso em 01/05/2018.

SINGLY, François de. Sociologia da Família Contemporânea. Tradução Clarice Ehlers Peixoto. Rio de Janeiro: Editora FGV, 2007.

STOER, Stephen R.; SILVA, Pedro. Escola-família: uma relação em processo de reconfiguração. Porto: Porto Editora, 2005.

\section{Credenciais da autora}

ASSIS, Cristina Ferreira de. Universidade Federal de Ouro Preto, graduada em história, Mestre em educação pela Universidade Federal de Ouro Preto. E-mail: cristinaferreiraassis@yahoo.com.br

Endereço para correspondência: Cristina Ferreira de Assis. E-mail: cristinaferreiraassis@yahoo.com.br

Como citar este artigo (Formato ABNT): ASSIS, Cristina Ferreira de. A relação família-escola em um território de alta vulnerabilidade social. Educação, Psicologia e Interfaces, v. 3, n.2, p. 21-33, 2019. DOI: https://doi.org/10.37444/issn-25945343.v3i2.135

Recebido: 04/03/2019.

Aceito: 20/6/2019.

Educação, Psicologia e Interfaces, Volume 3, Número 2, p. 21-33, Maio/Agosto, 2019.

ISSN: 2594-5343. DOI: https://doi.org/10.37444/issn-2594-5343.v3i2.135 